\title{
EVOLUÇÃO DA ÁREA DE GESTÃO DE PESSOAS EM UMA INSTITUI- ÇÃO DE ENSINO FEDERAL: DO OPERACIONAL AO ESTRATÉGICO
}

\author{
EVOLUTION OF THE MANAGEMENT AREA OF PEOPLE IN A FEDERAL \\ EDUCATION INSTITUTION: FROM OPERATIONAL TO STRATEGIC
}

\author{
José Adroaldo Parcianello ${ }^{1,}$ Roni Storti de Barros ${ }^{2}$, Andressa Fighera ${ }^{3}$, \\ Vania Medianeira Flores Costa ${ }^{4}$ e Leonardo Alves Maboni ${ }^{5}$
}

Recebido em: 17/06/2016

Aprovado em: 01/12/2016

\section{RESUMO}

A área de gestão de pessoas passou por profundas transformações nas últimas décadas, acompanhando as mudanças sociais vividas tanto na esfera privada quanto no âmbito público. Estudos sobre a evolução dessa área são importantes para compreender como esse processo ocorreu e como contribuiu para o desenvolvimento das organizações. Na esfera pública, a área de gestão de pessoas procurou acompanhar essas mudanças, passando do nível operacional para o nível estratégico nas organizações. Nesse contexto, este estudo objetivou analisar a área de gestão de pessoas de uma instituição federal de ensino, no período de 1988 a 2014, evidenciando as mudanças de atribuições ocorridas na Pró-Reitoria de Gestão de Pessoas. Para isso, realizaram-se uma pesquisa documental e entrevistas semiestruturadas com servidores que ocuparam a função de gestor de pessoas no período estudado. Os resultados apresentados demonstraram a evolução do tema na instituição analisada, evidenciada, principalmente, pelas mudanças de estrutura e nomenclatura, pela ampliação das atribuições e pelos depoimentos dos ex-gestores que atuaram na área.

Palavras-chave: Gestão Pública; Gestão de Pessoas; Mudança; Evolução; Administração estratégica;

\begin{abstract}
The area of people management passed by deep changes in recent decades, following social changes experienced in both the private as in the organizations of public sphere. Studies on the evolution this area are important for understanding how this process occurred and how it contributed to the development of organizations. In the public sphere the area of GP searched track these changes through the operational level to the strategic level in organizations. The study aimed to analyze the area of people management a Federal Educational Institution during the period from 1988 to 2014 and seek to demonstrate changes of assignments that occurred at Pró-Rectory of People Management. This is a documentary research and semi-structured interviews with servers who occupied the function of managing people in the study period. The results show the evolution of the theme in the institution, evidenced mainly by changes in structure and nomenclature, expansion of $d u$ ties, and testimonies of former managers who worked in the area.
\end{abstract}

Keywords: Public Management; People Management; Changing; Evolution; Strategic management;

1 Mestre em Gestão de Organizações Públicas. E-mail: parcianello@ufsm.br

2 Mestre em Gestão de Organizações Públicas. E-mail: ronistt@gmail.com

3 Mestranda em Gestão de Organizações Públicas. E-mail: andressafighera@gmail.com

4 Professora de Ensino Superior, lotada no Departamento de Ciências Administrativas. E-mail: vaniaflores2006@yahoo.com.br

5 Graduado em Direito, Assistente em Administração na Universidade Federal de Santa Maria E-mail: Imaboni@hotmail.com 


\section{Introdução}

As constantes transformações no ambiente organizacional têm modificado a forma de administrar as organizações públicas e privadas. Para Dutra (2006), a revolução tecnológica e a globalização alteraram o comportamento das organizações, levando-as a buscar novos modelos de gestão que compreendam as demandas existentes. A área de gestão de pessoas acompanha essas mudanças, evoluindo em suas formas e enfrentando desafios diante da diversidade da força de trabalho. Emerge, assim, uma nova maneira de gerir, que busca elaborar estratégias e políticas de forma alinhada à gestão organizacional. Especialmente entre as organizações públicas, também são adotadas novas práticas que acompanham a evolução no contexto em que estão inseridas. Na busca por eficiência, as organizações procuram modelos que atendam à realidade e adaptem-se às novas demandas sociais.

Diante disso, o presente estudo objetiva analisar a área de gestão de pessoas de uma instituição federal de ensino, evidenciando as mudanças ocorridas no período de 1988 a 2014, no que concerne às atribuições da Pró-Reitoria de Gestão de Pessoas. Trata-se de um tema de grande relevância, pois permite identificar de que forma as alterações no cenário organizacional contribuíram para o processo de surgimento e fortalecimento de novas tendências na área, esclarecendo como aconteceu sua evolução e relação com o movimento de mudança organizacional. Da mesma forma, esta pesquisa busca entender o passado e a maneira como foram construídas as transformações, possibilitando às organizações gerenciar mudanças futuras, por meio da diminuição dos efeitos de resistência a partir de uma reconstrução que pode ser baseada em contextos anteriores. Além disso, o estudo da evolução da área de gestão de pessoas em uma instituição federal de ensino também pode auxiliar demais instituições que estejam vivenciando esse processo a compreender o fenômeno.
A estrutura deste artigo está organizada em cinco etapas: contextualização da área de gestão de pessoas, metodologia do trabalho, caracterização da instituição federal de ensino estudada, apresentação e análise dos resultados e considerações finais.

\section{Contextualizando a área de gestão de pessoas}

A área de gestão de pessoas é uma preocupação crucial para qualquer empresa privada ou organismo público, com funções e atuação que estrategicamente contribuem para o crescimento de seus colaboradores de forma duradoura e abrangente. Os frutos colhidos quando se investe nos recursos humanos são inegáveis e sustentáveis. Nesse sentido, práticas e estratégias de atuação devem buscar a valorização do colaborador (DEMO, 2010)

Com o passar do tempo, as divisões ou os setores responsáveis pelo gerenciamento das pessoas começaram a preocupar-se com sua valorização. Esses setores se tornaram mais importantes dentro das organizações, na medida em que se percebeu sua relevância estratégica de competitividade, passando a assumir as atribuições mais variadas relativas à qualidade de vida e saúde do colaborador, à qualidade e às condições de trabalho e ao desenvolvimento do trabalhador. Nesse sentido, a literatura traz a necessidade de que práticas adotadas pela gestão de pessoas contribuam para o bem-estar dos colaboradores nas organizações (NISHII, LEPAK, \& SCHNEIDER, 2008; TURNER, HUEMANN, \& KEEGAN, 2008; DEMO, FOGAÇA, NUNES, EDREI, \& FRANCISCHETO, 2011; RUBINO, DEMO, \& TRALDI, 2011).

Desse modo, tendo em vista que, ao longo da evolução histórica da sociedade, a administração de pessoal dentro das organizações foi se tornando mais importante e valorizada, torna-se relevante estudar essa transformação gerada pela evolução da área, que é evidenciada pela Figura 1. 


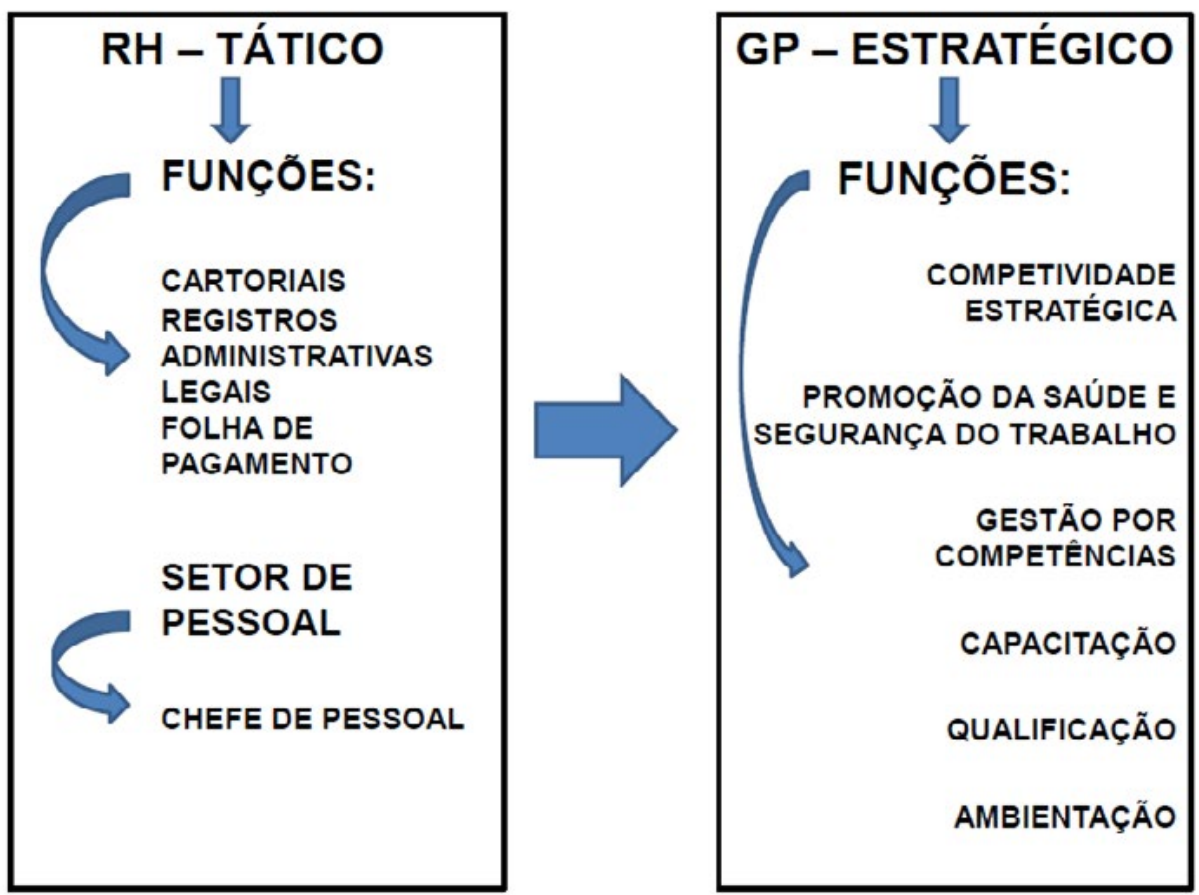

FIGURA 1 - Evolução da área de Gestão de Pessoas Fonte: autores do trabalho.

Ao abordar a evolução da área de Gestão de Pessoas, resultante de um processo de transformação, ressalta-se, inicialmente, a vigência do Decreto-Lei n. ${ }^{\circ}$. 5.452/43, que prevê a Consolidação das Leis Trabalhistas (CLT). Tal consolidação traz um novo conceito de administração de pessoal, originado na década de 1930. Na época, conforme demonstrado na Figura 1, as atividades da área resumiam-se, principalmente, a funções cartoriais, de registros, administrativas e legais, geralmente desempenhadas pelos proprietários das empresas.

É oportuno lembrar, ainda, que a CLT é um regimento relativo não somente à iniciativa privada, mas também aos funcionários públicos em casos específicos, e, historicamente, exerce forte influência sobre as legislações regimentais de trabalho destes funcionários, sendo usada inclusive para situações em que há lacuna legislativa ou em que o direito administrativo é omisso no trato, fato já previsto no artigo $8^{\circ}$ da referida Consolidação:

\begin{abstract}
Art. $8^{\circ}$ - As autoridades administrativas e a Justiça do Trabalho, na falta de disposições legais ou contratuais, decidirão, conforme o caso, pela jurisprudência, por analogia, por equidade e outros princípios e normas gerais de direito, principalmente do direito do trabalho, e, ainda, de acordo com os usos e costumes, o direito comparado, mas sempre de maneira que nenhum interesse de classe ou particular prevaleça sobre o interesse público (CLT, 1943, p. 2).
\end{abstract}

Assim, com o advento da CLT, ocorreram transformações significativas na área, e o então "setor de pessoal", conduzido pelo "chefe de pessoal", conforme é possível verificar na Figura 1, adquiriu novo sentido e novas atribuições, tal como a correta aplicação das legislações trabalhistas. Tendo em vista a exigência de conhecimento específico em legislação trabalhista, segundo Araújo (2006, p. 3), até o final da década de 1970, o cargo de chefe de pes- 
soal era exercido, na maioria das vezes, por advogados ou bacharéis em direito, que eram responsáveis pelas funções de admissão e demissão dos funcionários.

Os setores ou departamentos de pessoal tinham atuação mais específica e limitada, uma vez que atendiam principalmente às demandas trabalhistas necessárias para o adequado funcionamento da organização. Nessa conjuntura, ainda não era possível visualizar preocupação com condições razoáveis de trabalho ou mesmo com saúde e segurança dos trabalhadores. Diante dessas perspectivas, as ferramentas utilizadas na administração de pessoal sofreram mudanças mais sensíveis. Dentre elas, houve uma adaptação do sistema para receber a burocracia com seus caracteres, sendo eles: centralização, impessoalidade, hierarquia, meritocracia e separação entre o público e o privado (COSTA, 2008).

Com a obsolescência da administração pública burocrática, cada vez mais o setor público é direcionado a adotar uma abordagem gerencial baseada na descentralização, no controle de resultados, na competição administrada e no controle social direto (MARTINS, 1997 e ABRUCIO, 2007). Essa nova gestão privilegia o desempenho organizacional, os resultados e o gerenciamento dos recursos humanos, materiais, financeiros e informacionais. $\mathrm{E}^{\prime}$ um modelo mais flexível, que se adapta às mudanças sociais, econômicas, políticas e culturais (PEREIRA, 1996).

Para Pires e Macedo (2006), a cultura da maioria das organizações públicas brasileiras acaba por encaminhá-las à burocracia. Há de se ressaltar que as antigas práticas e modelos deixaram resquícios culturais de sua existência e que, por vezes, as práticas mais tradicionais ainda em uso podem entrar em conflito com as novas práticas de Gestão de Pessoas. Nesse contexto, Guimarães (2000) traz como desafio da administração pública transformar estruturas burocráticas em organizações alinhadas com os novos modelos de gestão estratégica.
Os novos modelos de gestão aos quais se refere a literatura, voltados ao corpo organizacional, surgiram por intermédio de experiências vivenciadas e à luz da falha de modelos antigos, como o exemplo da desburocratização. Para Ulrich (2000), em razão dos desafios enfrentados pelas organizações na dita "era do capital humano", os profissionais de Recursos Humanos precisam assumir papéis que incorporam as funções de criação e maximização de valor, além das funções de caráter tradicional que já são desempenhadas.

Nesse sentido, percebe-se um cenário onde cuidar e qualificar os colaboradores são atos que consistem em melhorias para os negócios da empresa ou da instituição. Por vezes, é mais competitiva a organização que tem colaboradores alinhados com seus objetivos e seu perfil do que aquela que possui equipamentos mais sofisticados ou outra vantagem qualquer. Tal premissa se verifica na abordagem literária de renomados autores da área de gestão de pessoas, como Guest (1987), Legge (2006), Boxall, Purcell e Wright (2007), Armstrong (2009) e Wilkinson, Bacon, Redman e Snell (2010), que estão de acordo que pessoas assumiram papel estratégico e de competitividade nas organizações.

Outro modelo, além do burocrático, que não pode passar despercebido, é o modelo de gestão por competências. Para Souza, Paixão e Souza (2011), trata-se de um conjunto de procedimentos que o gestor utiliza para identificar em um candidato um agrupamento de conhecimentos, habilidades e atitudes, que podem ser convertidas em resultados. Mueller (1996 apud Fernandes, 2006) considera que o objetivo do modelo de gestão por competências é desenvolver as competências das pessoas, o que, por extensão, aumenta o reservatório de competências à disposição da organização. A gestão por competências busca aproximar os objetivos organizacionais e pessoais, estimulando o alinhamento dos indivíduos com a organização. 
Dutra (2008, p. 24) confirma essa afirmação quando relata que "o estabelecimento das competências individuais deve estar vinculado à reflexão sobre as competências organizacionais, pois elas se influenciam mutuamente".

No âmbito do serviço público, sedimenta o conceito o Decreto n. ${ }^{\circ} 5.707$, de 23 de fevereiro de 2006, que institui a política e as diretrizes para o desenvolvimento de pessoal da administração pública federal direta, autárquica e fundacional, e o regulamenta dispositivos da Lei n. ${ }^{\circ} 8.112$, de 11 de dezembro de 1990, definindo a Gestão por Competências como a gestão da capacitação orientada para o desenvolvimento do conjunto de conhecimentos, habilidades e atitudes necessárias ao desempenho das funções dos servidores, visando ao alcance dos objetivos da instituição (BRASIL, 2006).

Há, ainda, a preocupação em desenvolver competências por meio de adequação, treinamento e qualificação dos colaboradores, para que estes desenvolvam aptidões necessárias à organização. Sobre o desenvolvimento dessas capacidades e a relevância de tal prática no setor público, é preciso colacionar o que menciona Amaral (2006, p. 554):

a nova política também estimula a aprendizagem e a disseminação do conhecimento, atribui ao conhecimento chave para a inovação e a melhoria da gestão pública, altera a separação entre o decidir e o executar, busca a qualidade de vida no trabalho (saúde física e emocional), valoriza a informação compartilhada, e finalmente cria alto grau de envolvimento de dirigentes e de servidores no ambiente de trabalho.

Para melhor funcionamento, o modelo do desenvolvimento de competências prevê também que o trabalhador seja recompensado por meio de remuneração por competência, evitando que, na busca de melhores salários, deixe a organização e, nesse caso, que o conhecimento adquirido seja desperdiçado ou, ainda pior, seja aproveitado por uma organização concorrente. Talvez essa seja a forma mais eficaz de incentivar o desenvolvimento de novas competências ou mesmo o aprimoramento de competências já apresentadas. Sobre isso, Lacombe (2006, p. 341) afirma que saber administrar o conhecimento é essencial para a sobrevivência do negócio da empresa e que a maior parte do conhecimento das organizações está na mente das pessoas que a compõem.

Em suma, para a implementação desse modelo com sucesso, é preciso estudar e mapear os processos, definindo a necessidade de competências e averiguando as práticas que têm bom funcionamento na organização como um todo. Além disso, conforme Lacombe (2006, p. 345), as organizações que aprendem têm capacidade para criar, adquirir e transferir conhecimentos, bem como para modificar seu comportamento. Dessa forma, pode-se chegar à conclusão de que a mudança de mentalidade deve abraçar a organização como um todo, e não somente àqueles que estão gerenciando os recursos humanos.

Pelo exposto, constata-se que a Gestão de Pessoas entende o colaborador como peça fundamental no processo de construção de toda a estratégia de competitividade de uma organização. As políticas de Gestão de Pessoas, com o intuito de valorizar os colaboradores, devem se modificar conforme a estratégia empresarial (Demo, 2010). Existem muitas ações trazidas pela literatura que caracterizam o reconhecimento dessa importância estratégica da Gestão de Pessoas e da valorização do colaborador. Dentre elas, cabe citar o exposto na Figura 2. 
Ações da Gestão de Pessoas Estratégica

\begin{tabular}{|l|}
\hline Mudança de nomenclatura \\
\hline Investimento de recursos em qualidade de vida e condições de trabalho do colaborador \\
\hline Resgate da imagem do colaborador \\
\hline Treinamento e desenvolvimento de competências \\
\hline Estímulo à inovação e à criatividade \\
\hline Valorização da eficiência e da qualidade na prestação de serviços \\
\hline Desenvolvimento de uma cultura gerencial \\
\hline Avaliação de desempenho \\
\hline Capacitação e qualificação \\
\hline Auditoria interna e sistema informacional de Recursos Humanos \\
\hline Mudança cultural: gestão de pessoas como agregador de valor \\
\hline Novos planos de carreira no serviço público federal \\
\hline Democratização das relações de trabalho \\
\hline Carreiras transversais \\
\hline
\end{tabular}

FIGURA 2 - Ações da Gestão de Pessoas Estratégica

Fonte: ARAÚJO, 2006.

Ante o exposto, evidenciou-se que a mudança do clima ou ambiente organizacional deve começar por uma mudança de mentalidade ou cultura, em direção a novas práticas de relações interpessoais, comunicação, criação de valores alinhados com os da instituição e busca de qualidade no produto ou serviço que oferece. Facilmente se percebe que, com uma mudança de cultura, alguns indicadores positivos acabam sendo trazidos à tona, tais como: maior produtividade, motivação para o trabalho, satisfação com a organização e qualidade do serviço prestado.

É fato que as transformações continuam e continuarão acontecendo a cada dia na área de Gestão de Pessoas, e o ritmo em que isso acontece tende a ser cada vez mais acelerado, já que a evolução tecnológica e a globalização exercem forte influência em tal cenário. Por isso, há necessidade de atualização constante e especialização dos profissionais para que estejam alinhados com os objetivos e as metas organizacionais e, mais do que isso, inclinados a adotar essa postura de suscetibilidade às inovações.

\section{Metodologia}

Trata-se de um estudo de caso aplicado a uma instituição de ensino federal no interior do Rio Grande do Sul, com um quadro de 4.689 servidores, entre docentes e técnico-administrativos em Educação, e 29.608 alunos. Além disso, é de natureza descritiva e de caráter qualitativo.

Como estratégia de pesquisa, utilizou-se o método de estudo de caso, tendo como unidade de análise a instituição estudada. Segundo Yin (2005), o estudo de caso possibilita a investigação de um fenômeno contemporâneo dentro de seu contexto da vida real, contribuindo para compreender melhor os processos organizacionais.

O presente trabalho dividiu-se em duas etapas, conforme demonstra o Quadro 1. 


\begin{tabular}{|c|c|c|c|}
\hline Etapas & Objetivos & Coleta de dados & Análise de dados \\
\hline $1^{\mathrm{a}}$ etapa & $\begin{array}{l}\text { Realizar levantamento } \\
\text { das legislações e dos } \\
\text { documentos institucionais } \\
\text { da instituição estudada. }\end{array}$ & Análise documental. & $\begin{array}{l}\text { Construção de um quadro- } \\
\text { resumo, de acordo com as } \\
\text { variáveis pesquisadas. }\end{array}$ \\
\hline $2^{\mathrm{a}}$ etapa & $\begin{array}{l}\text { Realizar entrevistas com } \\
\text { servidores que ocuparam } \\
\text { cargos de gestão ao longo } \\
\text { do período estudado. }\end{array}$ & $\begin{array}{l}\text { Três entrevistas } \\
\text { com perguntas } \\
\text { semiestruturadas, } \\
\text { baseadas no } \\
\text { referencial teórico } \\
\text { pesquisado. }\end{array}$ & $\begin{array}{l}\text { Análise de conteúdo, } \\
\text { contemplando as etapas } \\
\text { propostas por Bardin: } \\
\text { pré-análise; exploração do } \\
\text { material; tratamento dos } \\
\text { resultados, inferência e } \\
\text { interpretação. }\end{array}$ \\
\hline
\end{tabular}

Quadro 1 - Etapas da metodologia utilizadas no estudo

Fonte: autores do trabalho.

De acordo com o exposto, a primeira etapa envolveu a análise documental, em que foi possível realizar um levantamento das legislações e dos documentos institucionais da instituição estudada, bem como dos autores que abordam a evolução da área de Gestão de Pessoas. Na segunda etapa, ocorreu a coleta de dados, por meio de entrevistas com servidores que ocuparam cargos de gestão na atual Pró-Reitoria de Gestão de Pessoas ao longo do período estudado. $\mathrm{O}$ instrumento de coleta de dados utilizado foi um questionário com perguntas semiestruturadas, baseadas no referencial teórico pesquisado, que abordou as seguintes variáveis: cartoriais e operacionais, cartoriais e de registros, direitos e deveres, saúde, treinamento/capacitação, qualidade de vida no trabalho, direção/função, programa de desenvolvimento institucional (PDI), força de trabalho, unidades incorporadas e auditoria.

De posse dos dados coletados, após a transcrição das entrevistas, utilizou-se a análise de conteúdo, contemplando as três etapas propostas por Bardin (1979): pré-análise; exploração do material; tratamento dos resultados, inferência e interpretação.

\section{A instituição estudada}

De acordo com o estatuto da instituição estudada, trata-se de uma autarquia educacional de regime especial, vinculada ao Ministério da Educação, que possui sede no interior do estado do Rio Grande do Sul e foi criada pela Lei n. ${ }^{\circ} 3.834-\mathrm{C}$, de 14 de dezembro de 1960 . Tem como principais objetivos: estimular a pesquisa pura ou aplicada, incentivar o estudo dos problemas relacionados com o progresso da sua região geoeconômica, do estado e do país e colaborar com o poder público na solução dos problemas nacionais, objetivando o desenvolvimento do Brasil (IFE estudada ${ }^{6}, 2013$ ).

$\mathrm{O}$ seu quadro funcional é composto por 1.874 docentes e 2.815 técnico-administrativos em educação ativos, vinculados aos respectivos planos de carreira estabelecidos em legislação federal. Atualmente, conta com 29.608 estudantes de graduação, pós-graduação, ensino médio e ensino tecnológico, distribuídos entre as modalidades de ensino a distância e presencial (IFE estudada, 2013).

Conforme o artigo $9^{\circ}$ do Estatuto, a administração da instituição está dividida em três níveis: I - Superior: Reitoria e Conselhos Superiores; II - Intermediários: Unidades e Órgãos Suplementares; e III - Inferior: Departamentos. Destaca-se que a reitoria é composta do reitor, do vice-reitor, das pró-reitorias e dos órgãos suplementares centrais (IFE estudada, 2013). 


\section{Apresentação e análise dos dados}

A partir da etapa de análise documental, em que foram apreciadas as legislações e os documentos institucionais da instituição estudada, identificouse que, quando de sua criação, no início da década de 1960, a Divisão de Pessoal estava subordinada ao Departamento de Administração Central e contava com as seções de cadastro, administrativa, de direitos e vantagens, financeira e de classificação de cargos. Posteriormente, com a aprovação do regimento interno da instituição, em janeiro de 1972, a Divisão de Pessoal passou a Departamento de Pessoal (DP), subordinado à Pró-Reitoria de Administração. Em novembro de 1988, houve a aprovação do regimento geral da instituição, e ao então DP competia planejar, organizar, coordenar e supervisionar os trabalhos relativos às áreas de recrutamento, seleção e desenvolvimen- to de recursos humanos, classificação de cargos e empregos, bem como às áreas de caráter operacional, como legislação e pagamento. Ampliaram-se as atribuições, mas ainda era um órgão de registro, controle e supervisão das relações de trabalho da instituição com os servidores.

A gestão de 1994/1997 da instituição, acompanhando as tendências da área de Recursos Humanos, passou a preocupar-se com questões gerenciais e comportamentais da relação entre homem e trabalho. Nesse sentido, foi idealizado o Plano Permanente de Gestão de Recursos Humanos para a instituição, tendo como eixo principal a qualidade na construção da cidadania e o elemento humano como agente de mudanças. Assim, o DP foi reestruturado em Pró -Reitoria de Recursos Humanos (PRRH), contemplando melhorias na área, conforme exposto na Figura 2.

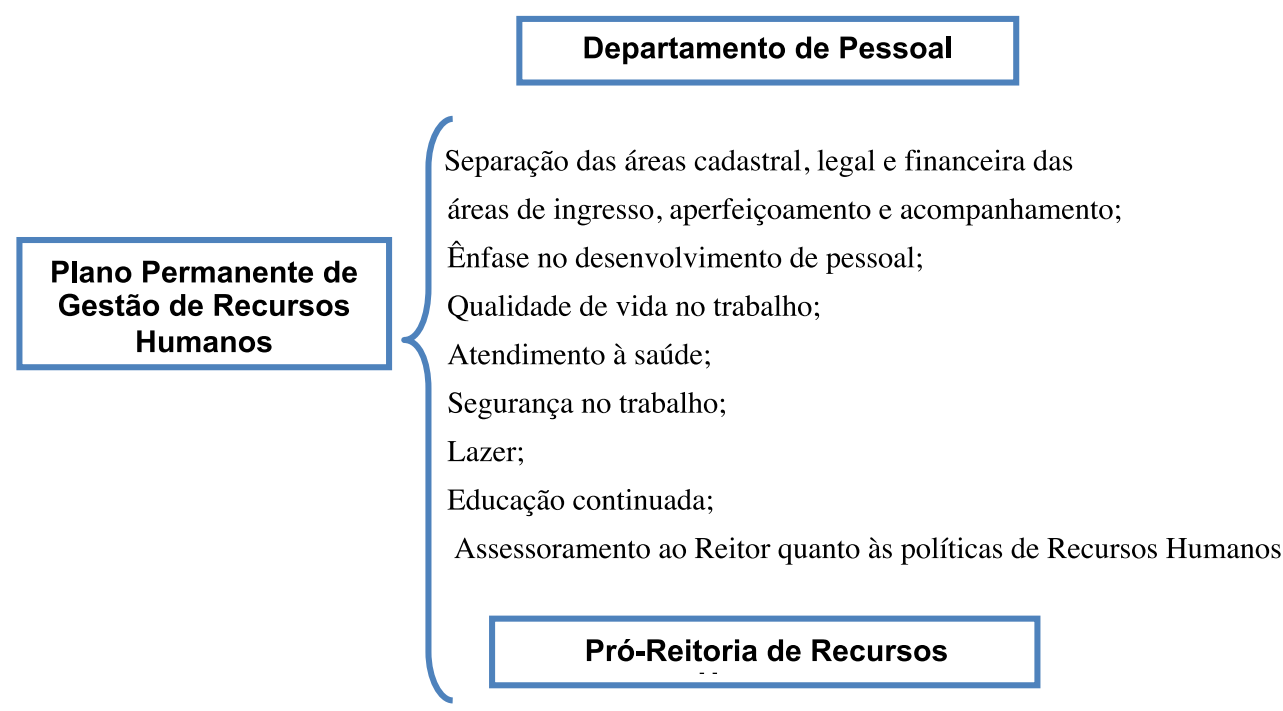

FIGURA 2 - Evolução do Departamento de Pessoal para Pró-Reitoria de Recursos Humanos Fonte: autores do trabalho. 
A mudança foi aprovada com a Resolução n. ${ }^{\circ}$ 28/96, do Conselho Universitário, que reestruturou o DP em PRRH, órgão de administração superior de direção e assessoria diretamente ligado ao Reitor. A transformação ocorrida tornouse um marco na instituição, dotando-a de uma estrutura compatível com o efetivo desenvolvimento de suas funções e permitindo o desenvolvimento de uma nova cultura organizacional de gestão de Recursos Humanos da instituição.

Frente às diversas e rápidas mudanças que ocorrem no mundo das organizações, visando acompanhar esse processo, especificamente na área de Gestão de Pessoas, foram necessários ajustes na estrutura organizacional da PRRH, tendo em vista as novas atividades que o setor passou a desenvolver. Tais mudanças foram sedimentadas com a alteração de denominação para Pró-Reitoria de Gestão de Pessoas (PROGEP). A elaboração da proposta de mudança ocorreu em consonância com o Plano de Desenvolvimento Institucional (PDI) (2011-2015) e com o Plano de Gestão (2010-2013), demonstrando compromisso institucional com a "valorização das pessoas e com o seu desenvolvimento profissional" (IFE estudada, 2010a, p. 37).

A aprovação da Resolução $\mathrm{n}^{\circ}$ 29/2012, que reestruturou a PRRH e alterou a sua denominação para PROGEP ocorreu em dezembro de 2012. No escopo da resolução, ficou explicitado o novo posicionamento da PROGEP na instituição:

a necessidade de determinar uma nova denominação para a Pró-Reitoria de Recursos Humanos que atenda as concepções atuais da área e as definições estratégicas da IFE e a necessidade de dotar a Pró-Reitoria de uma estrutura organizacional cujas subunidades tenham uma denominação e um conjunto adequado e coerente de atribuições capaz de atender ao escopo atual das atividades (IFE estudada, 2012, p. 67).

Após a obtenção dos dados a partir da análise documental, foi possível construir um quadro-resumo, em que se evidencia a evolução das variáveis elencadas neste estudo, do operacional ao estratégico, em cada uma das fases analisadas, sendo estas: DP, PRRH e PROGEP. 


\begin{tabular}{|c|c|c|c|}
\hline Variáveis & DP & PRRH & PROGEP \\
\hline $\begin{array}{l}\text { Operacionais e } \\
\text { de Registros }\end{array}$ & $\begin{array}{l}\text { - Recrutamento } \\
\text { e seleção de } \\
\text { recursos hu- } \\
\text { manos } \\
\text { - Classificação } \\
\text { de cargos e em- } \\
\text { pregos } \\
\text { - Legislação } \\
\text { - Pagamento }\end{array}$ & $\begin{array}{l}\text { - Manutenção do } \\
\text { - Controma de pagamentos } \\
\text { fícios } \\
\text { - Recrutamentónto seleção e alocação } \\
\text { de servidores } \\
\text { - Concursos técnico- } \\
\text { administrativos } \\
\text { - Classificação de } \\
\text { - Cargos } \\
\text { - Padastro } \\
\text { - Pensão e aposentadoria } \\
\text { Direitos e deveres }\end{array}$ & $\begin{array}{l}\text { - Manutenção do sistema de } \\
\text { - } \text { pagamentos } \\
\text { bentrole orçamentios } \\
\text { - Concurrio de } \\
\text { - } \text { administrativos e docentes } \\
\text { - Alocação de servidores } \\
\text { - Classificação de cargos } \\
\text { - Cadastro } \\
\text { - Pensão e aposentadoria } \\
\text { - Direitos e deveres }\end{array}$ \\
\hline $\begin{array}{l}\text { Assistência } \\
\text { Jurídica }\end{array}$ & $\begin{array}{l}\text { - Divisão de } \\
\text { legislação de } \\
\text { pessoal }\end{array}$ & - Assessoria Jurídica & - Advocacia-Geral da União \\
\hline $\begin{array}{l}\text { Saúde do Ser- } \\
\text { vidor }\end{array}$ & & - Perícia Médica & $\begin{array}{l}\text { - Perícia Oficial em Saúde- } \\
\text { Unidade } \\
\text { SIASS }\end{array}$ \\
\hline Variáveis & DP & PRRH & PROGEP \\
\hline $\begin{array}{l}\text { Treinamento/ } \\
\text { Capacitação }\end{array}$ & $\begin{array}{l}\text { Desenvolvi- } \\
\text { mento de recur- } \\
\text { sos humanos }\end{array}$ & $\begin{array}{l}\text { Educação, desenvolvimento, } \\
\text { integração, acompanhamento e } \\
\text { avaliação } \\
\text { - Programa de Integração } \\
\text { - Centro de Pesquisas e Desenvol- } \\
\text { vimento de Recursos Humanos } \\
\text { Regional }\end{array}$ & $\begin{array}{l}\text { Programa de Integração, } \\
\text { Formação e Desenvolvimento } \\
\text { Profissional- Programa Trans- } \\
\text { formar } \\
\text { - Levantamento de Necessida- } \\
\text { des de Capacitação- LNC }\end{array}$ \\
\hline $\begin{array}{l}\text { Qualidade de } \\
\text { Vida no Traba- } \\
\text { lho-QVT }\end{array}$ & - & 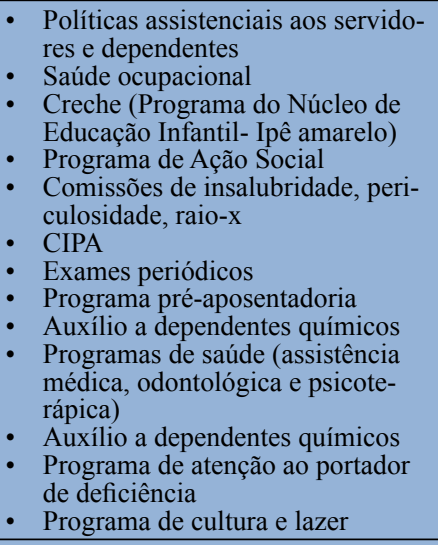 & $\begin{array}{l}\text { - Implantação da Unidade de } \\
\text { Atenção à Saúde dos Servido- } \\
\text { res- SIASS } \\
\text { - Políticas assistenciais aos ser- } \\
\text { vidores e dependentes } \\
\text { - Comissões de insalubridade, } \\
\text { periculosidade, raio-x e irra- } \\
\text { diação ionizante } \\
\text { - Exames periódicos } \\
\text { - Programa pré-aposentadoria } \\
\text { - Programas de saúde (assis- } \\
\text { tência médica, odontológica, } \\
\text { psicológica e serviço social) } \\
\text { - Programas de prevenção de } \\
\text { riscos ambientais } \\
\text { Programa de cultura e lazer }\end{array}$ \\
\hline $\begin{array}{l}\text { Papel da Ges- } \\
\text { tão de Pessoas }\end{array}$ & $\begin{array}{ll}\text { - } & \text { Vinculado ao } \\
\text { Pró- Reitor de } \\
\text { Administração } \\
\text { Operacional } \\
\end{array}$ & - Assessorar diretamente o Reitor & $\begin{array}{ll}\text { - Assessorar diretamente o } \\
\text { Reitor } \\
\text { Definir políticas de gestão de } \\
\text { pessoas }\end{array}$ \\
\hline PDI & - & - & $\begin{array}{l}\text { - Alinhamento estratégico: } \\
\text { valorização, capacitação, qua- } \\
\text { lificação } \\
\text { e avaliação dos servidores }\end{array}$ \\
\hline $\begin{array}{l}\text { Gestão da For- } \\
\text { ça de Trabalho }\end{array}$ & $\begin{array}{l}\text { - Controle do } \\
\text { MEC e MPOG }\end{array}$ & - Controle do MEC e MPOG & $\begin{array}{ll}\text { - } & \text { Autonomia } \\
\text { - Banco de Professor Equiva- } \\
\text { lente } \\
\text { Quadro de Referência } \\
\text { dos Servidores Técnico-Ad- } \\
\text { ministrativos das IFES- QRS- } \\
\text { TA } \\
\text { - Dimensionamento } \\
\end{array}$ \\
\hline $\begin{array}{l}\text { Órgãos de } \mathrm{Au}- \\
\text { ditoria }\end{array}$ & $\begin{array}{l}\text { - Siset/MEC e } \\
\text { TCU }\end{array}$ & $\begin{array}{l}\text { TCU, CGU, Auditoria Interna e } \\
\text { Ouvidoria da IFE estudada }\end{array}$ & $\begin{array}{l}\text { TCU, CGU, AUDIN/SEGEP/ } \\
\text { MP, MPF, Auditoria Interna e } \\
\text { Ouvidoria da IFE estudada }\end{array}$ \\
\hline
\end{tabular}

QUADRO 2 - Variáveis que demonstram a evolução do operacional ao estratégico Fonte: Processo Administrativo n. ${ }^{\circ}$ 23081.013031/2012-15. 
Percebe-se que o quadro-resumo vai ao encontro das bases teóricas estudadas, no sentido de que, na linha do tempo, as atribuições e ações da área de Gestão de Pessoas deslocaram-se de atividades essencialmente operacionais para ações de dimensão estratégica.

Oliveira (1998), citado na proposta de mudança de denominação e ajustes na estrutura organizacional da PRRH (Processo n. ${ }^{\circ}$ 23081.013031/2012-15, p. 34 ), comunga do entendimento de que as pessoas não podem ser consideradas recursos, como os recursos materiais e fisicos, sendo necessário valorizá-las como diferencial competitivo nas organizações.

A segunda etapa da metodologia aplicada envolveu entrevistas com servidores, que ocuparam cargos de gestores na Pró-Reitoria, ao longo do período estudado. O perfil dos servidores entrevistados, identificados por meio dos números 1, 2 e 3, está resumido no Quadro 3 , apresentado a seguir.

\begin{tabular}{|c|c|c|c|}
\hline Perfil/Gestor & 1 & 2 & 3 \\
\hline Estado Civil & Solteiro & Casado & Casado \\
\hline Área de Formação & $\begin{array}{c}\text { Ciências Sociais e } \\
\text { Humanas }\end{array}$ & $\begin{array}{c}\text { Ciências Sociais e } \\
\text { Humanas }\end{array}$ & $\begin{array}{c}\text { Ciências Sociais e } \\
\text { Humanas }\end{array}$ \\
\hline Cargo Efetivo & Administrador & Administrador & $\begin{array}{c}\text { Docente do Magisté- } \\
\text { rio Superior }\end{array}$ \\
\hline Nível de Escolaridade & Mestrado & Graduação & Doutorado \\
\hline $\begin{array}{c}\text { Ano que Ingressou na } \\
\text { instituição }\end{array}$ & 1984 & 1982 & 1995 \\
\hline $\begin{array}{c}\text { Período em que traba- } \\
\text { lhou na Pró-Reitoria }\end{array}$ & $1986-2001$ & $1989-1993$ & $2010-2013$ \\
\hline Período como Gestor & $\begin{array}{c}1993-1997 \\
2013-\text { atual }\end{array}$ & $2005-2010$ & $2010-2013$ \\
\hline
\end{tabular}

QUADRO 3 - Perfil dos servidores entrevistados

Fonte: entrevistas realizadas com os servidores.

As entrevistas foram realizadas no período de 10 a 20 de novembro do ano de 2014, sendo duas ocorridas nos locais de trabalho dos entrevistados e outra efetuada por e-mail, pois a servidora encontrava-se em processo de qualificação no exterior. Cada servidor foi questionado por uma pergunta inicial, sendo ela: "Como você, que foi gestor(a) de pessoas, analisa a evolução da área na instituição, desde o Departamento de Pessoal, passando pela Pró-Reitoria de Recursos Humanos, até chegar, atualmente, à Pró-Reitoria de Gestão de Pessoas, sob o ponto de vista das variáveis operacionais e de registros, assistência jurídica, saúde do servidor, treinamento/capacitação, qualidade de vida no trabalho, papel da gestão de pessoas, plano de desenvolvimento institucional, gestão da força de trabalho e órgãos de auditoria?". A con- dução da atividade foi realizada pelos autores do trabalho, conforme a descrição das experiências dos entrevistados e as variáveis abordadas.

Finalizadas as entrevistas, partiuse para a sua transcrição, com as descrições dos relatos dos entrevistados e, posteriormente, a análise do conteúdo obtido. A partir disso, apresenta-se, a seguir, a evolução das variáveis abordadas neste trabalho sob o ponto de vista de cada servidor enquanto gestor da atual PROGEP.

\subsection{Operacionais e de Registros}

Inicialmente, os departamentos de pessoal eram órgãos destinados a fazer cumprir as exigências legais vinculadas ao emprego, e a maioria dessas atividades envolviam atividades operacionais. Entretanto, movido por 
iniciativas de reforma e modernização e influenciados por empresas privadas, os órgãos públicos passaram a atuar mediante um conjunto de novos componentes e o uso da tecnologia na busca por melhores resultados (Diniz, et al.,
2009). Essa transformação está evidenciada no Quadro 4, nos depoimentos dos entrevistados, que relatam a evolução na forma de execução, desempenho e abrangência das atividades relacionadas à Pró-Reitoria.

\begin{tabular}{|c|c|c|}
\hline Variável & Entrevistado & Comentário \\
\hline \multirow{3}{*}{$\begin{array}{l}\text { Opera- } \\
\text { cionais e } \\
\text { de Regis- } \\
\text { tros }\end{array}$} & $\begin{array}{c}\text { Entrevista- } \\
\text { do } 1\end{array}$ & $\begin{array}{l}\text { "Sentada na minha mesa de diretora, eu quase não enxergava as } \\
\text { pessoas, porque era um volume de trabalho imenso". } \\
\text { "[...] a equipe passava boa parte do tempo registrando informa- } \\
\text { ções nas fichas de papel, e, quando se fazia necessária alguma } \\
\text { informação específica, era um esforço enorme e manual para } \\
\text { localizá-la. Além disso, rotinas que hoje são consideradas sim- } \\
\text { ples, como o cálculo do tempo de trabalho, demoravam cerca de } \\
\text { quinze dias para serem realizadas". } \\
\text { "[...] depois, começou a fase da informatização. Não tínhamos } \\
\text { as condições ideais pra fazer, ainda havia o computador grande, } \\
\text { o Super, e nós fomos buscar terminais descartados pelo Hospital } \\
\text { Universitário da Instituição, fios desciam do teto". }\end{array}$ \\
\hline & $\begin{array}{l}\text { Entrevista- } \\
\text { do } 2\end{array}$ & $\begin{array}{l}\text { "O servidor não aceitava mais apenas a parte operacional e pas- } \\
\text { sou a exigir mais da política de recursos humanos. Ampliaram- } \\
\text { se os horizontes, e, então, o antigo DP se abriu, e na estrutura } \\
\text { da Pró-Reitoria já se começou a pensar em qualidade de vida } \\
\text { do servidor, conceitos sobre gestão começaram a ser mudados". }\end{array}$ \\
\hline & $\begin{array}{c}\text { Entrevista- } \\
\text { do } 3\end{array}$ & $\begin{array}{l}\text { "Pode-se observar certa evolução das atividades desenvolvidas } \\
\text { pela Pró-Reitoria de Gestão de Pessoas, principalmente no que } \\
\text { tange à informatização de algumas atividades que anteriormen- } \\
\text { te eram realizadas essencialmente de modo manul". } \\
\text { "No entanto, não se pode desconsiderar que algumas ativida- } \\
\text { des operacionais continuam sendo desenvolvidas pela Unida- } \\
\text { de, haja vista as peculiaridades que envolvem a gestão pública, } \\
\text { como, por exemplo, as exigências impostas pela legislação". }\end{array}$ \\
\hline
\end{tabular}

QUADRO 4 - Comentários dos servidores entrevistados sobre a variável "Operacionais e de Registros".

Fonte: entrevistas realizadas com os servidores. 


\subsection{Assistência Jurídica}

A administração pública é regida pelo princípio da legalidade, que consiste na ideia de que todo e qualquer ato que emane da administração pública deve ter prévia determinação legal (Mello, 2000). No que cabe à legislação de pessoal, não é diferente, já que os gestores se encontram atrelados a esse princípio. Por meio dos relatos evidenciados no Quadro 5, percebe-se que é bastante dinâmica a legislação na área de pessoal e que, cada vez mais, atos e procedimentos são regulamentados por normativas, o que exige do gestor constante atualização da legislação e, muitas vezes, demanda auxílio dos órgãos de assistência jurídica e busca de esclarecimentos nos canais de apoio existentes.

\begin{tabular}{|c|c|c|}
\hline Variável & Entrevistado & Comentário \\
\hline \multirow{2}{*}{$\begin{array}{l}\text { Assistência } \\
\text { Jurídica }\end{array}$} & Entrevistado 1 & $\begin{array}{l}\text { "Houve uma perda no que tange a essa variável, pois na } \\
\text { época do Departamento de Pessoal havia uma Divisão de } \\
\text { Legislação, que funcionava como assessoria jurídica do } \\
\text { próprio Departamento, o que ajudava muito. E, hoje, existe } \\
\text { apenas uma relação com os procuradores da Advocacia ge- } \\
\text { ral da União, o que gera uma lacuna quanto ao assunto. [...] } \\
\text { Normalmente o dirigente de recursos humanos não tem a } \\
\text { formação em direito, então, a gente, enquanto gestor, tam- } \\
\text { bém precisa aprender muito nessa área, para dar conta dessa } \\
\text { legislação de pessoal, que é sempre muito dinâmica". }\end{array}$ \\
\hline & Entrevistado 3 & $\begin{array}{l}\text { "Há uma evolução que se refere à criação do Canal "Cndp", } \\
\text { um canal de comunicação voltado para os dirigentes de pes- } \\
\text { soal e de recursos humanos das Instituições Federais de Ensi- } \\
\text { no, onde circulam dúvidas sobre direitos e deveres dos servi- } \\
\text { dores, bem como a criação do canal SEGEP, pelo Ministério } \\
\text { do Planejamento, em que são divulgadas resenhas semanais } \\
\text { contendo legislações de Recursos Humanos. Essa evolução } \\
\text { representa um avanço na medida em que facilita a organiza- } \\
\text { ção e o acesso às publicações legais que envolvem direitos e } \\
\text { deveres dos servidores que atuam em organizações públicas". }\end{array}$ \\
\hline
\end{tabular}

QUADRO 5 - Comentários dos servidores entrevistados sobre a variável "Assistência Jurídica".

Fonte: entrevistas realizadas com os servidores. 


\subsection{Saúde do Servidor}

Chanlat (1995) aponta a existência de uma relação direta entre os modos de gestão adotados por uma organização e o processo saúde-doença. As organizações mais abertas e flexíveis, que propiciam ao trabalhador uma maior participação, são ambientes mais favoráveis à saúde. Estudos no campo de saúde do trabalhador apontam para a importância da autonomia, da liberdade, do controle e do domínio sobre o processo de trabalho (DEJOURS, 2004; GUIMARÃES, 2006; OLIVEIRA, 2006).

De acordo com os comentários dos gestores entrevistados, no Quadro 6 , a variável saúde do servidor acompanhou a evolução do modelo de gestão de pessoas, pois recebeu mais atenção no que tange à definição de políticas públicas, tais como a criação da Unidade SIASS - Subsistema Integrado de Atenção à Saúde do Servidor.

\begin{tabular}{|c|c|c|}
\hline Variável & Entrevistado & Comentário \\
\hline \multirow[b]{3}{*}{$\begin{array}{l}\text { Saúde do } \\
\text { Servidor }\end{array}$} & Entrevistado 1 & $\begin{array}{l}\text { "[...] não havia políticas voltadas para a área da Saúde. Era } \\
\text { nós que fazíamos um pouco esse papel, ouvir o servidor, por- } \\
\text { que nós não tínhamos o profissional com essa formação". }\end{array}$ \\
\hline & Entrevistado 2 & $\begin{array}{l}\text { "Houve a possibilidade de contratação do médico do trabalho, quan- } \\
\text { do começou a formar-se uma política de assistência ao servidor". }\end{array}$ \\
\hline & Entrevistado 3 & $\begin{array}{l}\text { "Após a criação da Unidade SIASS - Subsistema Integrado de } \\
\text { Atenção à Saúde do Servidor, verificou-se uma série de ativi- } \\
\text { dades e ações desenvolvidas pela Perícia Oficial em Saúde que } \\
\text { transcendem a realização de perícias médicas e odontológicas, } \\
\text { como pode-se citar: elaboração de manuais com orientações } \\
\text { aos servidores, elaboração de folders explicativos sobre pato- } \\
\text { logias, atendimento de demandas de outras unidades que par- } \\
\text { ticipam do SIASS e avaliação de candidatos com necessidades } \\
\text { especiais em concursos públicos e concursos vestibulares". }\end{array}$ \\
\hline
\end{tabular}

QUADRO 6 - Comentários dos servidores entrevistados sobre a variável "Saúde do Servidor".

Fonte: entrevistas realizadas com os servidores. 


\subsection{Qualidade de Vida no Trabalho}

Amorim (2010) e Ferreira, M. C. et al. (2009), abordam a importância da promoção da Qualidade de Vida no Trabalho (QVT) no Serviço Público, inserindo o tema em três perspectivas: a do bem-estar dos próprios servidores, a da satisfação dos usuários cidadãos e a da eficiência e eficácia dos serviços prestados nos órgãos públicos. Observando-se o Quadro 7, identifica-se que, especialmente, na instituição estudada, a variável $\mathrm{QVT}$ vem sendo trabalhada de forma crescente, já que, no então DP, não havia essa abordagem e que, hoje, alguns programas são oferecidos, inclusive, aos servidores inativos.

\begin{tabular}{|c|c|c|}
\hline Variável & Entrevistado & Comentário \\
\hline \multirow{3}{*}{$\begin{array}{l}\text { Qualidade } \\
\text { de Vida no } \\
\text { Trabalho }\end{array}$} & Entrevistado 2 & $\begin{array}{l}\text { "Foi o início da preocupação com o estado psíquico-emo- } \\
\text { cional dos servidores, também buscando que, dessa forma, } \\
\text { o servidor pudesse trazer maior retorno à Instituição. [...] } \\
\text { Nós criamos um Programa voltado ao tratamento de servi- } \\
\text { dores que tinham problemas com álcool, chamado Pró Vida. } \\
\text { Muitos servidores foram recuperados e vivem bem até os } \\
\text { dias de hoje, graças a esse apoio que encontraram". }\end{array}$ \\
\hline & Entrevistado 3 & $\begin{array}{l}\text { “[...] esse é um tema que não se esgota e é um assunto com- } \\
\text { plexo que deve ser avaliado constantemente procurando, de } \\
\text { modo contínuo e permanente, desenhar novos programas e } \\
\text { novas ações alinhados com as demandas dos servidores". }\end{array}$ \\
\hline & Entrevistado 1 & $\begin{array}{l}\text { "Nós oferecemos programas hoje, sem descuidar, inclusive, } \\
\text { dos servidores aposentados, este público que tanto contri- } \\
\text { buiu para o crescimento da instituição". }\end{array}$ \\
\hline
\end{tabular}

QUADRO 7 - Comentários dos servidores entrevistados sobre a variável "Qualidade de Vida no Trabalho".

Fonte: entrevistas realizadas com os servidores. 


\subsection{Treinamento/Capacitação}

A busca da eficiência no serviço público remete à importância da capacitação profissional, que é o "processo permanente e deliberado de aprendizagem, com o propósito de contribuir para o desenvolvimento de competências institucionais por meio do desenvolvimento de competências individuais" (BRASIL, 2006). Especialmente no âmbito da administração pública federal, no ano de 2006 foi publicado o Decreto n. $^{\circ}$ 5.707, que instituiu a Política Nacional de Desenvolvimento de Pes- soal, abordando orientações para o desenvolvimento permanente do servidor, visando à melhoria da qualidade dos serviços públicos prestados ao cidadão.

Analisando o Quadro 8, percebe-se que os entrevistados apontam a evolução da variável na instituição, relatando a criação de programas voltados ao desenvolvimento do servidor. Entretanto, também é demonstrado que $\mathrm{o}$ assunto precisa evoluir, visto que as competências desenvolvidas devem estar alinhadas às competências necessárias para o pleno desenvolvimento das atividades da instituição.

\begin{tabular}{|c|c|c|}
\hline Variável & Entrevistado & Comentário \\
\hline \multirow{3}{*}{$\begin{array}{l}\text { Treina- } \\
\text { mento/Ca- } \\
\text { pacitação }\end{array}$} & Entrevistado 2 & $\begin{array}{l}\text { "A criação do Levantamento das Necessidades de Capacita- } \\
\text { ção são evoluções que acompanham a tecnologia, a mudança } \\
\text { de conceitos e o crescimento da instituição". }\end{array}$ \\
\hline & Entrevistado 3 & $\begin{array}{l}\text { "A atividade assumiu um caráter estratégico na instituição. } \\
\text { Nós criamos o Programa Transformar, que abarcou uma sé- } \\
\text { rie de projetos voltados à valorização dos servidores, como a } \\
\text { Semana do Servidor Público, o Encontro Musical de Talentos } \\
\text { dos Servidores da Instituição, projetos de cunho social, entre } \\
\text { outros. [...] A realização do Mestrado Profissional em Gestão } \\
\text { de Organizações Públicas também é uma oportunidade para o } \\
\text { desenvolvimento de competências que promovam mudanças } \\
\text { nas organizações públicas". }\end{array}$ \\
\hline & Entrevistado 1 & $\begin{array}{l}\text { "Eu penso que, embora a gente ofereça bastantes cursos, acho } \\
\text { que ainda a gente deveria evoluir no sentido de oferecer as } \\
\text { capacitações mais ao encontro do que a instituição precisa. } \\
\text { Hoje a gente faz bastante coisa, mas ainda muito em cima do } \\
\text { interesse pessoal dos nossos servidores, e não se faz uma co- } \\
\text { nexão com aquilo que a instituição precisa". }\end{array}$ \\
\hline
\end{tabular}

QUADRO 8 - Comentários dos servidores entrevistados sobre a variável "Treinamento/ Capacitação".

Fonte: entrevistas realizadas com os servidores. 


\subsection{Papel da Gestão de Pessoas}

Para Cabrera (2008), o gestor de pessoas precisou evoluir da gestão de um vínculo simples para a compreensão da evolução das pessoas como trabalhadores do conhecimento e teve de aprender a trabalhar com um novo modelo de avaliação. Já Dutra (2008) afirma que a gestão estratégica de pessoas pode ser compreendida como a definição de políticas e diretrizes em relação aos recursos humanos para au- mentar a habilidade dos servidores e, consequentemente, do próprio órgão público, a fim de realizar seu trabalho de modo a alcançar seus objetivos.

Analisando o Quadro 9, pode-se observar a evolução do papel do gestor de pessoas, descrito pelos entrevistados, que passa a ocupar função estratégica junto à instituição, participando da tomada de decisões, bem como da definição de políticas voltadas à Gestão de Pessoas.

\begin{tabular}{|c|c|c|}
\hline Variável & Entrevistado & Comentário \\
\hline \multirow{3}{*}{$\begin{array}{l}\text { Papel da } \\
\text { Gestão de } \\
\text { Pessoas }\end{array}$} & Entrevistado 1 & $\begin{array}{l}\text { "A transformação do Departamento de Pessoal, vinculado à } \\
\text { Pró-Reitoria de Administração, em Pró-Reitoria de Recursos } \\
\text { Humanos, mostrou-se, na prática, bem-sucedida, pois a estru- } \\
\text { tura trouxe mais independência e evolução nas políticas vol- } \\
\text { tadas para os servidores". }\end{array}$ \\
\hline & Entrevistado 2 & $\begin{array}{l}\text { "A mudança na estrutura tornou a Pró-Reitoria mais ágil. A } \\
\text { Pró-Reitoria criou, digamos, vida própria; então, sem sombra } \\
\text { de dúvida, que esse assessoramento ao reitor ficou mais direto } \\
\text { e isso proporcionou a criação de uma política de recursos hu- } \\
\text { manos para a instituição". }\end{array}$ \\
\hline & Entrevistado 3 & $\begin{array}{l}\text { "Por meio das mudanças na estrutura organizacional, o gestor } \\
\text { de pessoas passou a assessorar o reitor, participando ativa- } \\
\text { mente das reuniões de pró-reitores e auxiliando na definição } \\
\text { de políticas voltadas à gestão de pessoas na instituição". }\end{array}$ \\
\hline
\end{tabular}

Fonte: entrevistas realizadas com os servidores. 
5.7 Plano de Desenvolvimento Institucional: A partir da Lei n. ${ }^{\circ} 10.861$, de 14 de abril de 2004, o Ministério da Educação introduziu como parte integrante do processo avaliativo das Instituições de Ensino Superior o planejamento estratégico, que se convencionou denominar de PDI
(IFE estudada, 2014). Conforme exposto no Quadro 10, a importância estratégica assumida pela área de Gestão de Pessoas encontra-se refletida no último PDI elaborado pela instituição, período 2010-2015, que possui, como um de seus eixos norteadores, a valorização das pessoas.

\begin{tabular}{|c|c|c|}
\hline Variável & Entrevistado & Comentário \\
\hline \multirow{3}{*}{$\begin{array}{l}\text { Plano de } \\
\text { Desenvol- } \\
\text { vimento } \\
\text { Institucio- } \\
\text { nal }\end{array}$} & Entrevistado 1 & \multirow{2}{*}{$\begin{array}{l}\text { Os entrevistados destacaram que, com a valorização da área } \\
\text { de Gestão de Pessoas, esta passou a assumir caráter estraté- } \\
\text { gico no Plano de Desenvolvimento Institucional. }\end{array}$} \\
\hline & Entrevistado 2 & \\
\hline & Entrevistado 3 & $\begin{array}{l}\text { "O PDI do período 2010-2015 da instituição possuiu, como } \\
\text { um dos eixos norteadores, a valorização das pessoas, con- } \\
\text { templando uma série de ações estratégicas, visando consoli- } \\
\text { dar a dimensão assumida pela área". }\end{array}$ \\
\hline
\end{tabular}

Desenvolvimento Institucional"

Fonte: entrevistas realizadas com os servidores. 


\subsection{Gestão da Força de Trabalho}

Buscando ajustar-se às demandas do novo século, o governo federal vem adotando uma política de gestão da força de trabalho que visa adequar a quantidade e a qualificação dos servidores às prioridades e áreas estratégicas de governo. Para que os órgãos alcancem os resultados esperados, estudos têm sido desenvolvidos para a definição de parâmetros que orientem o dimensionamento da força de trabalho (Moraes, et al.,2009).

No que tange à instituição estudada, o Quadro 11 indica, por meio dos comentários dos entrevistados, que a realidade se aproxima do cenário descrito por Moraes et al. (2009), ou seja, adequação no quantitativo de servidores e busca por metodologias que possam orientar o dimensionamento da força de trabalho existente.

\begin{tabular}{|c|c|c|}
\hline Variável & Entrevistado & Comentário \\
\hline \multirow{3}{*}{$\begin{array}{l}\text { Gestão da } \\
\text { Força de } \\
\text { Trabalho }\end{array}$} & Entrevistado 2 & $\begin{array}{l}\text { "Antes surgia vaga, tinha que pedir autorização para o Ministé- } \\
\text { rio do Planejamento para poder prover aquela vaga. A criação } \\
\text { do Banco de Professor Equivalente e do Quadro de Referên- } \\
\text { cia dos Servidores Técnico-Administrativos, pelo MEC foi um } \\
\text { salto sensacional para a instituição. Agilizou em termos da re- } \\
\text { posição da força de trabalho". }\end{array}$ \\
\hline & Entrevistado 3 & $\begin{array}{l}\text { "Foi um avanço significativo, tanto em termos quantitativos, } \\
\text { quanto no que se refere à autonomia nos processos de gestão } \\
\text { da força de trabalho da instituição. [...] Com a implantação do } \\
\text { Programa REUNI, houve um aumento do número de vagas } \\
\text { docentes e de técnicos administrativos para as IFES, visando } \\
\text { atender a ampliação de vagas e a criação de novos cursos. En- } \\
\text { tretanto, há muito a ser desenvolvido no que se refere ao di- } \\
\text { mensionamento da força de trabalho". }\end{array}$ \\
\hline & Entrevistado 1 & $\begin{array}{l}\text { “A área de Gestão de Pessoas precisa evoluir na questão do } \\
\text { dimensionamento da força de trabalho. E nós estamos come- } \\
\text { çando a trabalhar isso, com uma metodologia em parceria com } \\
\text { a Pró-Reitoria de Planejamento, vamos fazer um piloto aqui } \\
\text { dentro da Pró-Reitoria de Gestão de Pessoas, a princípio, em } \\
\text { uma coordenadoria. E isso é uma coisa que eu digo, eu fiquei } \\
\text { tantos anos longe daqui, fiquei } 15 \text { anos fora, e esse é um pro- } \\
\text { blema, não digo um problema, mas um assunto que não evo- } \\
\text { luiu. [...] Foi criado um Fórum de Gestão de Pessoas, formado } \\
\text { pelas Instituições Federais de Ensino, que abordará, em um de } \\
\text { seus eixos, o dimensionamento da força de trabalho, tendo em } \\
\text { vista a necessidade de evolução no tema". }\end{array}$ \\
\hline
\end{tabular}

QUADRO 11 - Comentários dos servidores entrevistados sobre a variável "Gestão da Força de Trabalho".

Fonte: entrevistas realizadas com os servidores. 


\section{9 Órgãos de Auditoria}

A função controle está presente em todos os níveis das organizações, atuando em todos os processos. Megginson (1986) define controle como o processo de garantir que os objetivos organizacionais e gerenciais sejam cumpridos, isto é, a maneira de fazer com que as coisas aconteçam do modo planejado. Nesse sentido, a auditoria, segundo Justen (2005), é o conjunto de técnicas que visa avaliar a gestão pública, pelos processos e resultados gerenciais, e a aplicação de recursos públicos mediante a confrontação entre uma situação encontrada e um determinado critério técnico, operacional ou legal.

O Quadro 12, a seguir, aponta a crescente atuação dos órgãos de auditoria externos e internos na avaliação da gestão pública, além da exigência maior de transparência nos processos adotados pela instituição.

\begin{tabular}{|c|c|c|}
\hline Variável & Entrevistado & Comentário \\
\hline \multirow{3}{*}{$\begin{array}{l}\text { Órgãos de } \\
\text { Auditoria }\end{array}$} & Entrevistado 2 & $\begin{array}{l}\text { "Na época, havia um controle maior dos órgãos auditores so- } \\
\text { bre as aposentadorias e seus fundamentos". }\end{array}$ \\
\hline & Entrevistado 3 & $\begin{array}{l}\text { "Haviam as auditorias mensais realizadas na folha de paga- } \\
\text { mento, bem como as auditorias realizadas pelos órgãos de } \\
\text { controle externo, tais como CGU, TCU, MPF, e internos, } \\
\text { como a auditoria interna da instituição e a ouvidoria. [...] A } \\
\text { criação destas unidades de controle interno na instituição de- } \\
\text { monstra a preocupação em manter controles operacionais e } \\
\text { de gestão adequados e alinhados às exigências legais e dos } \\
\text { órgãos de controle". }\end{array}$ \\
\hline & Entrevistado 1 & $\begin{array}{l}\text { "O sistema de trilhas de auditoria na folha de pagamento é } \\
\text { realizado quase que simultaneamente, pois, à medida que } \\
\text { a instituição está lançando as informações da folha de pa- } \\
\text { gamento, já está sendo questionada sobre a origem desses } \\
\text { lançamentos. [...] Atualmente, as pessoas têm mais acesso } \\
\text { aos órgãos de controle e investigações, o que facilita no en- } \\
\text { caminhamento de denúncias e exige mais transparência dos } \\
\text { órgãos públicos". }\end{array}$ \\
\hline
\end{tabular}




\section{Considerações finais}

A construção deste artigo foi uma tentativa de demonstrar a evolução da área de Gestão de Pessoas, no período de 1988 a 2014, em uma Instituição Federal de Ensino. Em decorrência das significativas mudanças sociais, do desenvolvimento das Tecnologias de Informação e Comunicação e das demandas internas e externas que influenciaram a área nas últimas décadas, pode-se observar a crescente diversidade de novos papéis assumidos. $\mathrm{O}$ crescimento da instituição estudada, com o Programa de Apoio a Planos de Reestruturação e Expansão das Universidades Federais (Reuni), a partir de 2008, também desempenhou significativo fator na evolução da Gestão de Pessoas. Além disso, os conceitos trazidos pela nova Gestão Pública para a melhoria na qualidade dos serviços prestados ao cidadão-cliente também contribuíram para a evolução e mudança cultural.

Diversos subsistemas de acompanhamento e controle vinculados à folha de pagamento, auditoria do gasto público, qualidade de vida e saúde e segurança do trabalho, por demandas do governo federal, acrescentaram de forma significativa novas atribuições para a área. Na esteira da transparência pública, nota-se o aumento no número de órgãos de controle social, como, por exemplo, Controladoria-Geral da União (CGU) e Ministério Público Federal (MPF). No âmbito interno, também foram estruturados a Auditoria Interna e a Ouvidoria.

Comparando-se as antigas atividades do então DP com as atuais na PROGEP, pode-se afirmar que a multidisciplinariedade de profissionais para cumprir essas atribuições se faz necessária. Destaca-se que a área de Gestão de Pessoas está alinhada com o PDI na linha estratégica da valorização, capacitação, qualificação e avaliação dos servidores - o dirigente dessa área se encontra em uma posição de assessoria, estando muito próximo ao dirigente máximo na defi- nição das políticas de Gestão de Pessoas. Nesse sentido, é evidente a preocupação com a qualificação e capacitação dos servidores quanto ao desenvolvimento e à implantação de um programa específico para o alcance desse objetivo.

Ainda, em relação à sustentabilidade, nota-se que a evolução na área de Gestão de Pessoas, demonstrada no presente artigo, também se vincula ao eixo temático QVT, da Agenda Ambiental na Administração Pública (A3P) e do Plano de Logística Sustentável da instituição estudada.

Retomando o objetivo proposto neste trabalho, o de analisar a área de Gestão de Pessoas de uma Instituição Federal de Ensino, no período de 1988 a 2014, evidenciando as mudanças de atribuições ocorridas na PROGEP, verifica-se que este foi alcançado, podendo ser demonstrado pelas mudanças na estrutura organizacional na nomenclatura do órgão, pelo incremento considerável de atribuições e pelas falas dos ex-gestores da área.

Tendo em vista o método e as ferramentas utilizadas neste estudo, bem como as permanentes discussões sobre o tema e o desenvolvimento da área de Gestão de Pessoas, sugerem-se novos estudos de casos sobre a evolução de Gestão de Pessoas. Estes, certamente, irão surgir, pois, provavelmente, existirão novas fases na área, com características diferentes das que hoje se vivencia, adaptadas às novas realidades de sociedade em geral, às tecnologias e aos serviços públicos.

Por fim, ressalta-se que este trabalho apresenta como limitação o fato de que as entrevistas foram realizadas apenas com os gestores (pró-reitores) do período estudado. Sugere-se a continuidade deste estudo com os servidores lotados na área de Gestão de Pessoas que vivenciaram essas mudanças. 


\section{Referências}

ABRUCIO, F. Trajetória recente da gestão pública brasileira: um balanço crítico e a renovação da agenda de reformas. RAP Edição Especial Comemorativa, p. 67-86, 2007.

AMARAL, H. K. Desenvolvimento de competências de servidores na administração pública brasileira. Revista do Serviço Público, v. 57, n.4, p. 549-563, 2006.

AMORIM, T. G. N. Qualidade de Vida no Trabalho: preocupação também para servidores públicos? Revista Eletrônica de Ciência Administrativa, v.9, n. 1, p. 35-48, 2010.

Armstrong, Michael. Armstrong's handbook of human resource management practice. 11. ed., London: Kogan Page, 2009.

ARAÚJO, Luis C. Gestão de Pessoas: Estratégia e Integração Organizacional. São Paulo: Atlas, 2006.

BARDIN, Laurence. Análise de conteúdo. Lisboa: Edições 70, 1979.

Boxall, P., Purcell, J., \& Wright, P. Human resource management: scope, analysis and significance. In: BOXALL, P.; PURCELL, J.; WRIGHT, P. (Orgs.), The oxford handbook of human resource management. New York: Oxford University Press, 2007.

Brasil, Consolidação das Leis do Trabalho (CLT), 1943. Disponível em: $<$ http://www.planalto.gov.br/ccivil 03/ decreto-lei/del5452.htm>. Acesso em: 10 jun. 2014.

Decreto 5.707, 2006. Disponível em: <http://www.planalto.gov. br/ccivil 03/ Ato2004-2006/2006/Decreto/D5707.htm $>$. Acesso em: 13 jun. 2014.

CABRERA, Luiz C. Gestão de recursos humanos na administração pública: A perspectiva da Gestão de Pessoas. [S.1.:s.n.] 2008.
CHANLAT, J.F. Modos de gestão, saúde e segurança no trabalho. In: DAVEL, E.; VASCONCELLOS, J.(Orgs.), Recursos Humanos e Subjetividade. Rio de Janeiro: Vozes, 1995. p.118-128

CODA, Roberto. Psicodinâmica da vida organizacional: motivação e liderança. 2. ed. São Paulo: Atlas, 1997.

Demo, Gisela. Políticas de gestão de pessoas nas organizações: o papel dos valores pessoais e da justiça organizacional. 3. ed. São Paulo: Atlas, 2010.

Demo, G., Fogaça, N., Nunes, I., Edrei, L., \& Francischeto, L. Políticas de gestão de pessoas no novo milênio: cenário dos estudos publicados nos periódicos da área de administração entre 2000 e 2010. Revista de Administração Mackenzie, v. 12, n.5, p.15-42, 2011.

DEJOURS, C. Entre sofrimento e reapropriação: o sentido do trabalho In: LANCMAN, S.; SZNELWAR, L. (Org.), Christophe Dejours: da psicopatologia à psicodinâmica do trabalho. Rio de Janeiro: Editora Paralelo $15 /$ Editora Fiocruz, 2004, p.303-316.

DINIZ, E.H., BARBOSA, A.F., JUNQUEIRA, A.R.B., \& PRADO, O. O governo eletrônico no Brasil: perspectiva histórica a partir de um modelo estruturado de análise. Revista de Administração Pública, v. 43, n. 1, p. 23-48, 2009.

DUTRA, Joel S. Gestão de Pessoas: Modelo, Processos, Tendências e Perspectivas. São Paulo: Atlas, 2006.

Competências: Conceitos e instrumentos para a gestão de pessoas na empresa moderna. São Paulo: Atlas, 2008.

FERREIRA, M. C., ALVES, L., TOSTES, N. Gestão de Qualidade de Vida no Trabalho (QVT) no Serviço Público Federal: O Descompasso entre Problemas e Práticas Gerenciais. Psicologia: Teoria e Pesquisa. v. 25 n.3, p. 319-327, 2009. 
FERNANDES, Bruno H. Competências e desempenho organizacional: o que há além do Balanced Scorecard. São Paulo: Saraiva, 2006.

Guest, D. Human resource management and industrial relations. Journal of Management Studies, v.24, n.5, p.503$521,1987$.

GUIMARÃES, T. A. A nova administração pública e a abordagem da competência. Revista de Administração Pública, v. 34, n. 3, p. 125-140, 2000.

GUIMARÃES, M. C. Controle no trabalho: uma reflexão sobre antigas e novas formas de controle e suas consequências sobre os trabalhadores. Revista de Gestão da USP, v.13, n.1, p.1-10, 2006.

JUSTEN FILHO, Marçal. Curso de direito administrativo. São Paulo: Saraiva, 2005.

Legge, K. Human resource management. In: ACKROYD, S; BATT, R; THOMPSON, P; TOLBERT, P.S. (Eds.), The Oxford handbook of work and organization. New York: Oxford University Press, 2006, p. 220-241.

MARTINS, H. Burocracia e a revolução gerencial: a Persistência da Dicotomia entre Política e Administração. Revista do Serviço Público, v. 48, n. 1, p. 42-78, 1997.

MEGGINSON, Leon; MOSLEY, Donald C.; PIETRI Jr, Paul H. Administração: conceitos e aplicações. São Paulo: Harper \& How do Brasil, 1986.

MELLO, Celso A. B. Curso de Direito Administrativo, 12. Ed. São Paulo: Malheiros, 2000.

MINISTÉRIO DO PLANEJAMENTO, ORÇAMENTO E GESTÃO. Avanços e Desafios na Gestão da Força de Trabalho no Poder Executivo Federal, 2015. Disponível em: $<$ http://www.planejamento.gov.br/secretarias/upload/ Arquivos/seges/arquivos/091229 avancos_desafios.pdf $>$. Acesso em: $1 \overline{5}$ abr. $201 \overline{5}$.
Nishii, L. H., Lepak, D. P., \& Schneider, B. Employee attributions of the "Why" of HR practices: their effects on employee attitudes and behaviors, and customer satisfaction. Personnel Psychology, v. 61, n.3, p. 503-545, 2008.

OLIVEIRA, S., JACQUES, M.G.C. Políticas e práticas de gestão de saúde: recortes sobre o trabalho de teleatendimento no Rio Grande do Sul. Revista Brasileira de Saúde Ocupacional, v.31, n.114, p.63-72, 2006.

PEREIRA, L.C.B. Da Administração Pública Burocrática à Gerencial. Revista do Serviço Público, v.47, n.1, p. 7-40, 1996.

PIRES, J. C. S., MACEDO, K. B. Cultura organizacional em organizações públicas no Brasil. Revista de Administração Pública, v. 40, n. 1, p. 81105, 2006.

Rubino, T., Demo, G., \& Traldi, M. T. F. 2011. As políticas de gestão de pessoas influenciam o bem-estar no trabalho? In: CONGRESSO IBEROAMERICANO DE PSICOLOGIA DAS ORGANIZAÇÕES E DO TRABALHO, I, Florianópolis, 2011. Anais...Florianópolis, Brasil.

SOUZA, D. A., PAIXÃO C. R., SOUZA, E. A. B. Benefícios e dificuldades encontradas no processo de seleção de pessoas: uma análise do modelo de seleção por competências, sob a ótica de profissionais da área de gestão de pessoas. Gestão \& Regionalidade, v. 27, n. 80, p. $45-58,2011$.

Turner, R., Huemann, M., \& Keegan, A. Human resource management in the project-oriented organization: employee well-being and ethical treatment. The International Journal of Project Management, v. 26, n.5, p.577-585, 2008

ULRICH, Dave. Recursos humanos estratégicos: novas perspectivas para os profissionais de RH. São Paulo: Futura, 2000. 
UNIVERSIDADE FEDERAL DE SANTA MARIA. Estatuto, 2014. Disponível em: <http://site.ufsm.br/arquivos/uploaded/arquivos/d526dcf3-df9c4d04-ae38.022695bef98c.pdf $>$. Acesso em: 27 maio 2014.

. UFSM em Números, 2014.

Disponível em: $<$ http://portal.ufsm. br/indicadores/index $>$. Acesso em: 27 maio 2014.

Portal Documentos, 2014. Disponível em: <http://portal.ufsm. br/documentos/documentos/index.html?action=downloadArquivo\&idArquivo=759>. Acesso em 04 jul. 2014.

Wilkinson, A., Bacon, N., Redman, T., \& Snell, S. The sage handbook of human resource management. London: Sage Publications, 2010.

YIN, Robert K. Estudo de Caso: planejamento e métodos. 3. ed. Porto Alegre: Bookman, 2005. 